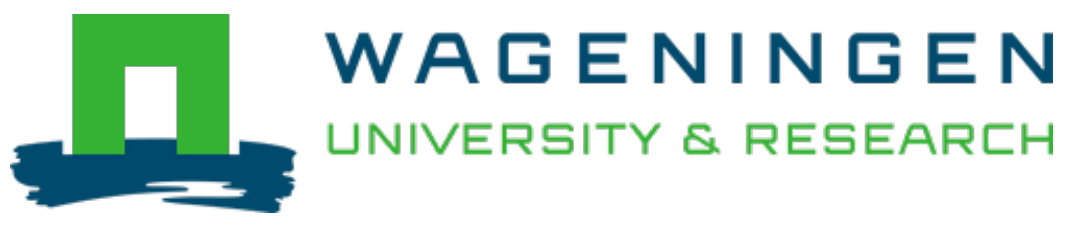

\title{
Removing top leaves increases yield and nutrient uptake in maize plants
}

\author{
Nutrient Cycling in Agroecosystems
}

Raza, Muhammad Ali; Werf, Wopke; Ahmed, Mukhtar; Yang, Wenyu

https://doi.org/10.1007/s10705-020-10082-w

This publication is made publicly available in the institutional repository of Wageningen University and Research, under the terms of article $25 \mathrm{fa}$ of the Dutch Copyright Act, also known as the Amendment Taverne. This has been done with explicit consent by the author.

Article $25 \mathrm{fa}$ states that the author of a short scientific work funded either wholly or partially by Dutch public funds is entitled to make that work publicly available for no consideration following a reasonable period of time after the work was first published, provided that clear reference is made to the source of the first publication of the work.

This publication is distributed under The Association of Universities in the Netherlands (VSNU) 'Article $25 \mathrm{fa}$ implementation' project. In this project research outputs of researchers employed by Dutch Universities that comply with the legal requirements of Article $25 \mathrm{fa}$ of the Dutch Copyright Act are distributed online and free of cost or other barriers in institutional repositories. Research outputs are distributed six months after their first online publication in the original published version and with proper attribution to the source of the original publication.

You are permitted to download and use the publication for personal purposes. All rights remain with the author(s) and / or copyright owner(s) of this work. Any use of the publication or parts of it other than authorised under article $25 \mathrm{fa}$ of the Dutch Copyright act is prohibited. Wageningen University \& Research and the author(s) of this publication shall not be held responsible or liable for any damages resulting from your (re)use of this publication.

For questions regarding the public availability of this publication please contact openscience.library@wur.nl 


\title{
Removing top leaves increases yield and nutrient uptake in maize plants
}

\author{
Muhammad Ali Raza (D) - Wopke van der Werf • Mukhtar Ahmed • \\ Wenyu Yang
}

Received: 16 March 2020 / Accepted: 6 July 2020/Published online: 18 July 2020

(C) Springer Nature B.V. 2020

\begin{abstract}
Intraspecific competition for light affects nutrient uptake of maize, especially during the seed filling phase (from the blistering-stage to physiological-maturity). Partial leaf removal only affects the top leaves and improves the light-environment, which could then enhance nutrient uptake during the seed filling phase. However, there is a shortage of quantitative information on the yield effects of such a management measure. A 3-year field trial was conducted to evaluate the impact of different leaf removal treatments (no removal of leaves (D0: control),
\end{abstract}

Muhammad Ali Raza and Wopke van der Werf considered as joint first authors.

Electronic supplementary material The online version of this article (https://doi.org/10.1007/s10705-020-10082-w) contains supplementary material, which is available to authorized users.

M. A. Raza · W. Yang $(\bowtie)$

College of Agronomy, Sichuan Agricultural University, No. 211, Huimin Road, Wenjiang District,

Chengdu 611130, Sichuan, People's Republic of China e-mail: mssiyangwy@sicau.edu.cn

W. van der Werf

Centre for Crop Systems Analysis, Wageningen

University, PO Box 430, 6700 AK Wageningen,

The Netherlands

\section{Ahmed}

Department of Agricultural Research for Northern Sweden, Swedish University of Agricultural Sciences, Umeå, Sweden removal of two leaves (D2), removal of four leaves (D4), and removal of six leaves (D6) from maizecanopy) on total dry matter accumulation, and nitrogen, phosphorus, and potassium uptake at the blistering-stage and physiological-maturity, plus seed number per plant, seed weight, and seed yield at physiological maturity. Compared to D0, at physiological-maturity, D2 significantly increased total dry matter accumulation (by 9\%), and uptake of nitrogen (by 5\%), phosphorus (by 10\%), and potassium (by $4 \%$ ); while excessive leaf removal treatments considerably reduced dry matter accumulation and nutrient uptake. Importantly, during the seed filling phase of maize, treatment D2 significantly enhanced the uptake of nitrogen, phosphorus, and potassium by $76 \%, 40 \%$, and $65 \%$, respectively, compared to control. Treatment D2 increased seed number per plant (by $6.4 \%$, from 448 under D0 to 477 in D2) and seed weight (by $5.7 \%$ ). Relative to control, maize in D2 had 12\%, 14\%, and $11 \%$, higher seed-yields in 2017, 2018, and 2019, respectively, and it also improved the economic profit when taking into account labor costs.

Graphic abstract Graphical representation of changes in light transmittance, photosynthesis, nutrient uptake, carbohydrate, and dry matter accumulation in maize plants as affected by different leaf removal treatments. Treatment codes represent no defoliation (D0: control), removal of two leaves (D2), removal of four leaves (D4), and removal of six leaves (D6) from the top of maize canopy. Yellow and green arrows show the light environment and leaf area of maize 
plants. The black arrows represent the regulating directions of leaf removal treatments on maize growth and development in this paper. The graphical abstract clearly demonstrates the significant improvement of optimum leaf removal treatment (D2) as compared to control (D0). The red and blue arrows show the relevant increase and decrease of the mentioned components between the optimal leaf removal and control.

Keywords Maize $\cdot$ Nitrogen $\cdot$ Phosphorus ·

Potassium $\cdot$ Seed filling-phase

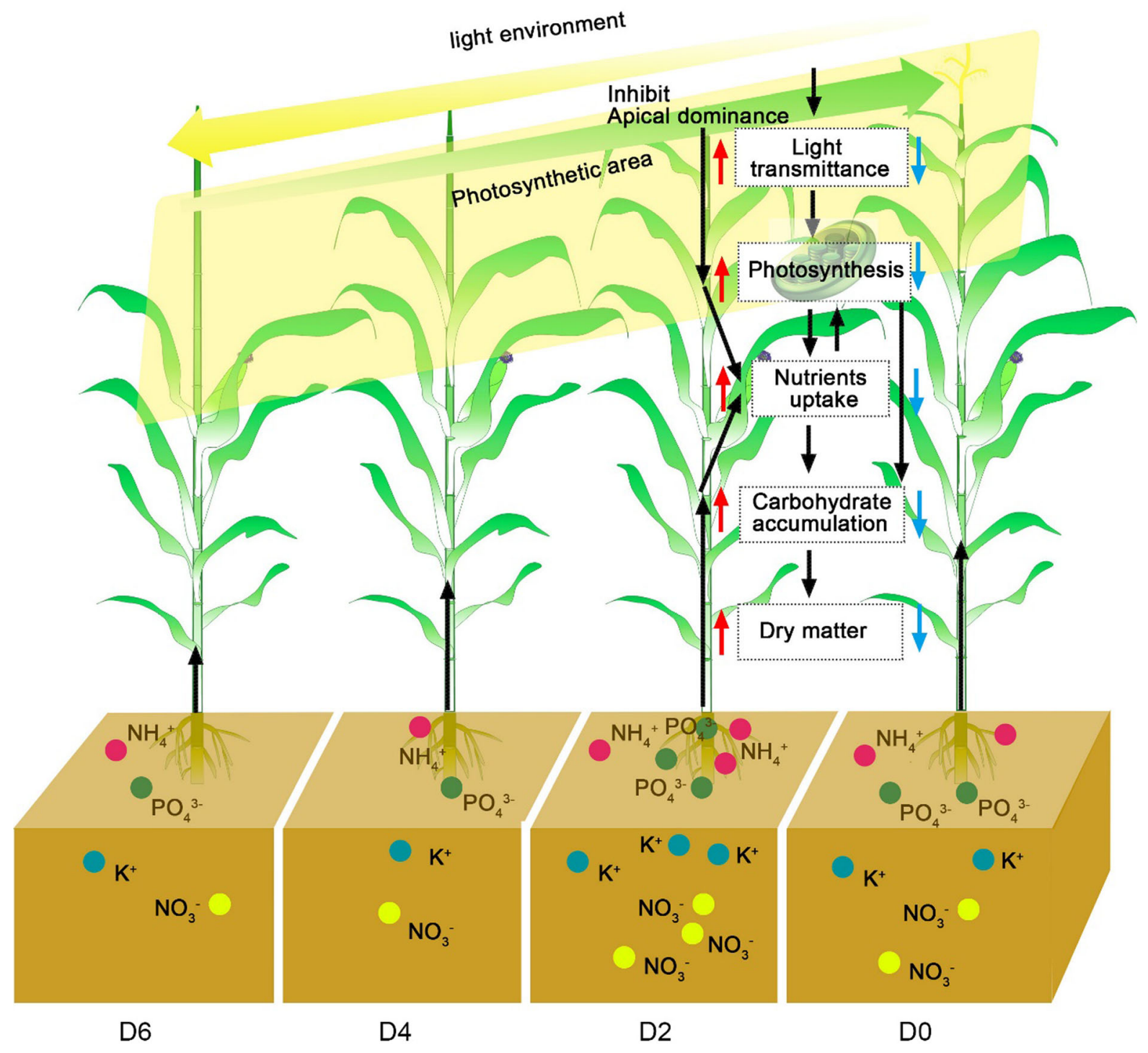




\section{Introduction}

Solar radiation is a critical factor in driving crop production (Connor et al. 2011). In Monsoon-influenced humid subtropical areas of China (Sichuan), the amount of total solar radiation reaching agricultural fields ranges from 3350 to $4190 \mathrm{MJ} \mathrm{m}^{-2}$ year $^{-1}$, which is below the average total solar radiation values of $5900 \mathrm{MJ} \mathrm{m}^{-2}$ year $^{-1}$ for China as a whole (Zhou et al. 2019). Shading conditions are ubiquitous in agricultural fields due to the high planting density needed for full light capture, and almost all the crop plants experience shading during their growth period (Valladares and Niinemets 2008). Shading inhibits leaf area development (Wu et al. 2017) and decreases leaf photosynthesis (Yang et al. 2017), which ultimately reduces total biomass production (Raza et al. 2019c) and crop yield (Feng et al. 2019). These results lead to the conclusion that shading adversely affects the growth and development of crop plants during their lifetime. To avoid mutual shading between individual plants, local farmers plant crops at low densities, i.e., wheat (Triticum aestivum L.) at $240 \times 10^{4}$ plants $\mathrm{ha}^{-1}$, rice (Oryza sativa L.) at $13 \times 10^{4}$ plants $\mathrm{ha}^{-1}$, maize (Zea mays L.) at $54 \times 10^{4}$ plants $\mathrm{ha}^{-1}$, and soybean (Glycine $\max \mathrm{L}$.) at $10 \times 10^{4}$ plants ha $^{-1}$.

Crop yields are affected (positively or negatively) by source strength (production of photosynthates by leaves) or sink strength (the ability of reproductive organs to grow and store assimilates) (Borrás et al. 2004). There are several biotic (genotype, insect, pest, and disease) and abiotic (temperature, rainfall, sunlight, and nutrients) factors that influence the sourcesink relations in crop plants (Borrás et al. 2004; Miralles and Slafer 2007). Nitrogen (N), phosphorus $(\mathrm{P})$, and potassium $(\mathrm{K})$ are macro-nutrients driving growth and development of crops (Raza et al. 2019c). Adequate uptake of these nutrients from the soil directly or indirectly affects the carbohydrate production and partitioning, and also influence the sourcesink relation in crop plants (Arduini et al. 2006). Optimum $\mathrm{N}$ content in crop plants can improve leaf development as well as photosynthesis, and delay the process of leaf senescence during the grain filling stages in maize (Liu et al. 2017; Muchow and Davis 1988). Optimum $\mathrm{N}$ content can also increase the dry matter translocation towards reproductive parts (Guitman et al. 1991; Prystupa et al. 2004; Vouillot and
Devienne-Barret 1999). P influences the seed number, seed weight, and seed yield of crop plants (Elliott et al. 1997) and affects dry matter accumulation in vegetative and reproductive parts differently than N (Batten 1992; Prystupa et al. 2004). Similarly, K uptake is essential for enhancing maize production, and previous literature reveals that adequate uptake of $\mathrm{K}$ in crops significantly improves the growth, dry matter production, and partitioning of photoassimilates to economic parts, i.e., seeds (Iqbal and Hidayat 2016).

More than $80 \%$ of the total $\mathrm{N}$ is accumulated in cereals during the vegetative stage (Papakosta and Gagianas 1991). Thus, the $\mathrm{N}$ absorbed before the reproductive stage in cereal crops can account for 70-90\% of the total $\mathrm{N}$ in seeds (Cox et al. 1985; Heitholt et al. 1990). Post-vegetative uptake of $\mathrm{N}$ by maize seeds is decreased by reduced net photosynthesis from silking to physiological maturity (Liu et al. 2017), caused by the mutual shading and decrease in leaf $\mathrm{N}$ content which restricts the light transmittance at the middle strata leaves of maize (Raza et al. 2019a). In contrast to nitrogen accumulation, $\mathrm{P}$ absorption takes place throughout the growth of crop plants (Batten 1992), and a significant amount of $P$ is translocated to seeds from stem and leaves during the seed filling phase (Papakosta 1994). Therefore, understanding nutrient accumulation during the seed filling phase of crops is crucial for sustainable crop production. Nutrient accumulation depends on crop species, variety, and environment (sunlight). It has been reported that nutrient accumulation may be more affected by the growing conditions (growing space and light environment) of crops than by other factors (Raza et al. 2019c). However, previous research has neglected the importance of nutrient accumulation during the seed filling of maize, especially in low light regions. Besides, studies have not considered the impact of leaf removal treatments (which only affects the top leaves of maize) on the nutrient accumulation of maize, especially during the seed filling phase.

Light deficiency during seed filling limits the photosynthesis potential of maize leaves because the upper canopy reduces light transmittance by $19 \%$ to lower leaves, depending on the variety (Karam et al. 2010). Leaf removal has been reported to affect nutrient uptake in plants. For example, removal of two leaves from the top of the maize canopy enhanced the $\mathrm{N}$ accumulation and distribution in maize grains (Liu et al. 2017), and also improved the uptake of $\mathrm{P}$ and $\mathrm{K}$ at 
maturity under an intercropping system (Raza et al. 2019c). Previously, it has been confirmed that middle strata leaves of maize contribute more carbohydrates and nutrients to seeds because they are more effective at utilizing sunlight than other leaves (Kefu 1981; Liu et al. 2015). Moreover, past crop yield improvements were associated with increased nutrient accumulation, which is an essential component of seeds (Sinclair et al. 2019). However, the impact of leaf removal treatments on nutrient $(\mathrm{N}, \mathrm{P}$, and $\mathrm{K}$ ) accumulation was not determined, especially during the seed filling phase in low light regions that naturally receive less sunlight in the field. Thus, the low light quantity is a major constraint for maize production, especially during the seed filling phase of maize growth, and there is little knowledge regarding the potential beneficial effects of leaf removal during this phase.

Therefore, in this experiment, we evaluated the effect of mutual shading intensity by maize plants, manipulated by leaf removal treatments, on the uptake of major nutrients and seed yield of maize, especially during the seed filling phase (from blistering stage to physiological stage) under the comparatively low sunlight conditions that are prevalent in Monsooninfluenced humid subtropical climates. The main objectives of this experiment were to (1) assess the influence of leaf removal treatments on dry matter accumulation, $\mathrm{N}, \mathrm{P}$, and $\mathrm{K}$ uptake during the seed filling phase of maize; and (2) study the impact of leaf removal treatments on yield and yield components of maize.

\section{Materials and methods}

\section{Experimental site description}

The field experiments were carried out during the growing seasons of 2017, 2018, and 2019 at the research area of Sichuan Agricultural University in Yaan, Sichuan Province, China $\left(29^{\circ} 59^{\prime} \mathrm{N}, 103^{\circ} 00^{\prime} \mathrm{E}\right.$, $620 \mathrm{~m}$ above sea level). The climate is classified as a monsoon-influenced continental climate with a dry winter and wet summer, according to the KöppenGeiger classification system (Peel et al. 2007). The region is a typically humid subtropical monsoon climate with $1200 \mathrm{~mm}$ annual rainfall that mainly occurs from June to September. The research site has a mean temperature of $16.2{ }^{\circ} \mathrm{C}$. Monthly mean temperature and average rainfall during the experimental years of 2017, 2018, and 2019, are shown in Figure S1 (Supplementary File-1). According to the initial soil test (at sowing), the soil has a $\mathrm{pH}\left(\mathrm{H}_{2} \mathrm{O}\right)$ of 6.7 , a total $\mathrm{N}$ of $1.6 \mathrm{~g} / \mathrm{kg}$, a total $\mathrm{P}$ of $1.4 \mathrm{~g} / \mathrm{kg}$, a total $\mathrm{K}$ of $16.4 \mathrm{~g} / \mathrm{kg}$, and organic content of $29.9 \mathrm{~g} / \mathrm{kg}$. The available $\mathrm{N}, \mathrm{P}$, and $\mathrm{K}$ content of experimental soil were $317 \mathrm{mg} / \mathrm{kg}, 42 \mathrm{mg} / \mathrm{kg}$, and $382 \mathrm{mg} / \mathrm{kg}$, respectively, in the $0-0.3 \mathrm{~m}$ soil layer.

\section{Experimental design and field management}

The experimental design was a randomized complete block design (RCBD) with three replicates. This fieldstudy had four leaf removal levels: no removal of leaves (D0: control), removal of two leaves (D2), removal of four leaves (D4), and removal of six leaves (D6) from the top of maize canopy (Figure S2; Supplementary File-2). Leaf removal treatments were applied when maize was at the silking stage (R1, 30th June 2017; 28th June 2018; and 1st July 2019, $85 \pm 4$ days after sowing). In this study, we used the maize hybrid Zhenghong-505 (semi-compactmaize type), which has six leaves above the ear. The distance between rows and plants was maintained at $0.7 \mathrm{~m}$ and $0.24 \mathrm{~m}$, respectively, resulting in a planting density of 60,000 plants per hectare. Each plot was 6 meters long and 5.6 meters wide $\left(\approx 36 \mathrm{~m}^{2}\right)$. Maize was sown on April 4th-7th from 2017 to 2019, harvested on August 13th-17th from 2017 to 2019. The maize seeds were sown manually at a depth of $0.05 \mathrm{~m}$. The fertilizers were applied at 10 days after sowing, at rates of $135 \mathrm{~kg} \mathrm{~N} \mathrm{ha}^{-1}$ as urea, $72 \mathrm{~kg} \mathrm{P}$ $\mathrm{ha}^{-1}$ as calcium superphosphate, and $90 \mathrm{~kg} \mathrm{~K} \mathrm{ha}^{-1}$ as potassium sulfate. At 45 days after sowing, the second dose of $\mathrm{N}$ was applied at a rate of $75 \mathrm{~kg} \mathrm{~N}^{-1}$ as urea. No irrigation was applied during the study; the crop was grown under rainfed conditions. Light transmittance $(\%)$ was measured in different leaf removal treatments to quantify the changes in the light environment of maize plants. To measure light transmittance, sensors (LI-191SA quantum sensors, LICOR Inc., Lincoln, NE) were placed on the horizontal arm of an observing scaffold above the maize canopy and at the ground level at blistering stage (R3) and physiological maturity stage (R6) in all experimental plots. The light transmittance of each treatment was measured three times in every treatment from 10:00 a.m. to 12:00 p.m. on a sunny day. From 
these data, the light transmittance was calculated by using the following formula:

Light transmittance $(\%)=\frac{L_{G}}{L_{T}} \times 100$

where $L_{T}$ is the light at the top of the maize canopy, and $L_{G}$ is the light at ground level.

\section{Measurements}

\section{Dry matter and seed yield}

For the analysis of dry matter accumulation $\left(\mathrm{t} \mathrm{ha}^{-1}\right)$ and translocation in leaves, stem, cob, and seeds ( $\mathrm{g}$ plant $^{-1}$ organ), five consecutive maize plants from the central rows of each treatment in every replicate were harvested (manually with shears) at blistering stage (R3; $7 \pm 2$ days after the leaf removal treatments from 2017 to 2019) and physiological maturity stage (R6; $44 \pm 3$ days after the leaf removal treatments from 2017 to 2019). Then the collected samples were divided into the leaf, stem, and cob at R3 and leaf, stem, cob, and seed at R6. At each sampling stage, all samples were dried at $65^{\circ} \mathrm{C}$ to reach a constant weight. Seed yield was measured by harvesting twenty-four maize ears from each treatment in every replicate. All ears were dried in the open air for 7 days and then threshed manually. Finally, seed yield parameters, including seed number per plant and seed weight (mg), and seed yield, were determined.

\section{Nutrient uptake}

At R3 and R6, after the measurement of dry matter, the same plant samples (leaf, stem, cob, and seed) were used to measure the $\mathrm{N}, \mathrm{P}$, and $\mathrm{K}$ content in plant parts using the procedure described previously (Raza et al. 2019c). The N, P, and K accumulation were measured as the product of $\mathrm{N}, \mathrm{P}$, and $\mathrm{K}$ content in each plant organ and dry matter of each plant organ. The N, P, and $\mathrm{K}$ yield were estimated from the summation of $\mathrm{N}$, $\mathrm{P}$, and $\mathrm{K}$ content in all plant parts. We also measured the total $\mathrm{N}, \mathrm{P}$, and $\mathrm{K}$ uptake during the seed filling phase from R3 to R6 by subtracting the total N, P, and $\mathrm{K}$ accumulation at $\mathrm{R} 3$ from $\mathrm{N}, \mathrm{P}$, and $\mathrm{K}$ accumulation at R6.

\section{Economic analysis}

An economic analysis was done using partial budgeting to assess the economic viability of leaf removal treatments for maize production. Total expenses for the production of maize included land rent, seedbed preparation, cost of maize seeds, cost of applied fertilizer ( $\mathrm{N}, \mathrm{P}$, and $\mathrm{K})$, thinning and weeding, cost of labor for leaf removal, harvesting, and threshing. Costs were based on local rates. Gross income was calculated by multiplying the measured yields with the local market prices of maize in 2017, 2018, and 2019. Net income (NI) was determined by subtracting all expenses from the gross income (Raza et al. 2018a).

\section{Statistical analysis}

The field study was performed for three consecutive years during the summer season of 2017, 2018, and 2019 with three replications for each treatment. Statistical analyses were conducted using Statistix 8.1. Significant differences were measured by using ANOVA in combination with LSD (least significance difference) test. The significance of differences was evaluated at $P<0.05$. Tables report the means and standard errors of calculated means, based on the three replicates per treatment. In contrast, the pairwise comparisons were made using the LSD test based on the assumption of homogeneity of variance across treatments.

\section{Results}

Light transmittance

The light transmittance within maize plants under different leaf removal treatments is shown in Fig. 1. In this experiment, the highest light transmittance was obtained in treatment D6 (removal of six leaves), while the lowest light transmittance was noted under treatment D0 (no removal of leaves). Overall, averaged over the 3 years, the light transmittance was enhanced by $28 \%, 67 \%$, and $107 \%$ at R3, and $15 \%$, $43 \%$, and $64 \%$ at R6 in D2, D4, and D6, respectively. 
(a) Blistering Stage (R3)

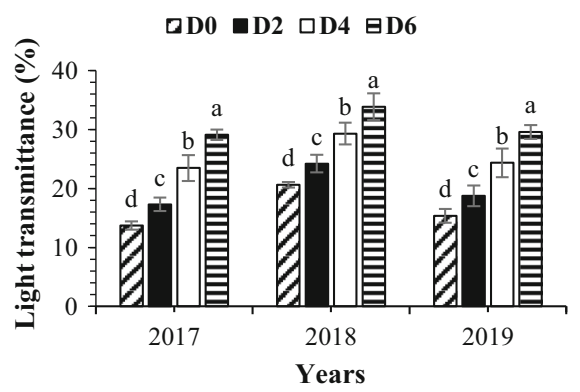

Fig. 1 The light transmittance of maize plants at the blistering stage (a) and physiological maturity (b) as affected by different leaf removal treatments during 2017, 2018, and 2019. Treatment codes represent no defoliation (D0: control), removal of two

Dry matter accumulation

Across different leaf removal levels and sampling stages, maize plants accumulated dry matter of $10.05 \mathrm{t}$ $\mathrm{ha}^{-1}$ and $16.39 \mathrm{t} \mathrm{ha}^{-1}$ in D0, $10.12 \mathrm{tha}^{-1}$ and $17.78 \mathrm{t}$ $\mathrm{ha}^{-1}$ in D2, $9.03 \mathrm{t} \mathrm{ha}^{-1}$ and $14.05 \mathrm{t} \mathrm{ha}^{-1}$ in D4, and $8.36 \mathrm{t} \mathrm{ha}^{-1}$ and $12.58 \mathrm{t} \mathrm{ha}^{-1}$ in D6 at R3 and R6, respectively (Table 1). Different leaf removal treatments not only affected the dry matter accumulation of maize plants but also changed the dry matter translocation in plant parts of maize (Table 1). For instance, averaged over the years, relative to D0, treatment D2 increased the dry matter of cob and seed by $15 \%$ and $11 \%$, respectively, at R6. However, excessive leaf removal treatments D4 and D6 significantly reduced the total dry matter (by 30\%), and dry matter content of leaves (by $31 \%$ ), stem (by 15\%), cob (by 28\%), and seed (by 23\%) at R6 as compared to D0, suggesting that the reduction in source size caused a significant decrease in the accumulation of dry matter and translocation to economic parts (cob and seeds).

\section{Nitrogen uptake}

Table 2 presents the $\mathrm{N}$-yield and $\mathrm{N}$ content in various organs of maize under different treatments. On average, over the years, the highest $\mathrm{N}$-yield $163.7 \mathrm{~kg} \mathrm{ha}^{-1}$ at R3 and $197.0 \mathrm{~kg} \mathrm{ha}^{-1}$ at R6 were found in D0 and D2, respectively. The lowest N-yield $131.3 \mathrm{~kg} \mathrm{ha}^{-1}$ at $\mathrm{R} 3$ and $142.9 \mathrm{~kg} \mathrm{ha}^{-1}$ at $\mathrm{R} 6$ was observed under treatment D6. We also calculated the $\mathrm{N}$ content in leaves, stem, cob, and seeds of maize in (b) Physiological Maturity (R6)

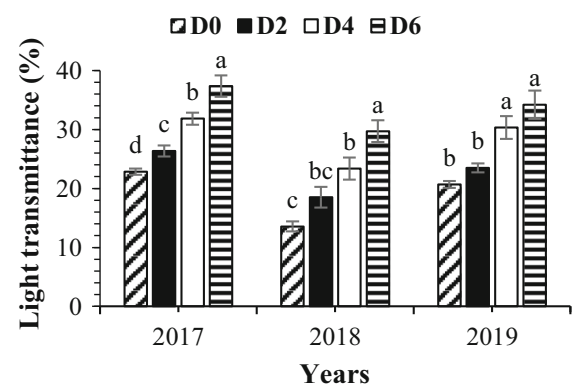

leaves (D2), removal of four leaves (D4), and removal of six leaves (D6) from the top of maize canopy. Means are averaged over three replicates

different leaf removal treatments. Results showed that the $\mathrm{N}$ content of maize seeds increased, while that of leaves, stem, and cob decreased between R3 and R6 in all treatments. At R3, the highest $\mathrm{N}$ content of leaves $\left(97.0 \mathrm{~kg} \mathrm{ha}^{-1}\right)$ and cob $\left(19.7 \mathrm{~kg} \mathrm{ha}^{-1}\right)$ was obtained in D0, while that of the stem $\left(62.9 \mathrm{~kg} \mathrm{ha}^{-1}\right)$ was found in D6 treatment. At R6, the maximum $\mathrm{N}$ content of leaves $\left(57.4 \mathrm{~kg} \mathrm{ha}^{-1}\right)$, cob $\left(7.3 \mathrm{~kg} \mathrm{ha}^{-1}\right)$, and seeds (105.2 $\mathrm{kg} \mathrm{ha}^{-1}$ ) was recorded in D2, while that of the stem $\left(51.3 \mathrm{~kg} \mathrm{ha}^{-1}\right)$ was noticed under D6 treatment. To determine the differences in total $\mathrm{N}$ uptake during the seed filling phase from R3 to R6, the total N uptake of maize plants in different leaf removal treatments was calculated (Fig. 2a), and different leaf removal treatments had a significant impact on $\mathrm{N}$ uptake in maize. At R6, the maximum total $\mathrm{N}$ uptake (39.6 kg ha $\mathrm{kg}^{-1}$ in $2017,36.4 \mathrm{~kg} \mathrm{ha}^{-1}$ in 2018 , and $53.2 \mathrm{~kg} \mathrm{ha}^{-1}$ in 2019) from R3 to R6 was measured in $\mathrm{D} 2$, whereas the minimum total $\mathrm{N}$ uptake (11.9 $\mathrm{kg} \mathrm{ha}^{-1}$ in $2017,7.2 \mathrm{~kg} \mathrm{ha}^{-1}$ in 2018 , and $15.6 \mathrm{~kg} \mathrm{ha}^{-1}$ in 2019) was obtained under treatment D6. Overall, averaged over the years, treatment D2 increased the total $\mathrm{N}$ uptake by $76 \%$ as compared to D0, while it decreased by $31 \%$ in D4 and 53\% in D6, suggesting that $\mathrm{N}$ uptake during the seed filling phase in maize was closely related to the changes in source size and microclimate of crops.

Phosphorus uptake

Table 3 shows the P-yield and P content in different plant organs of maize under different treatments. 


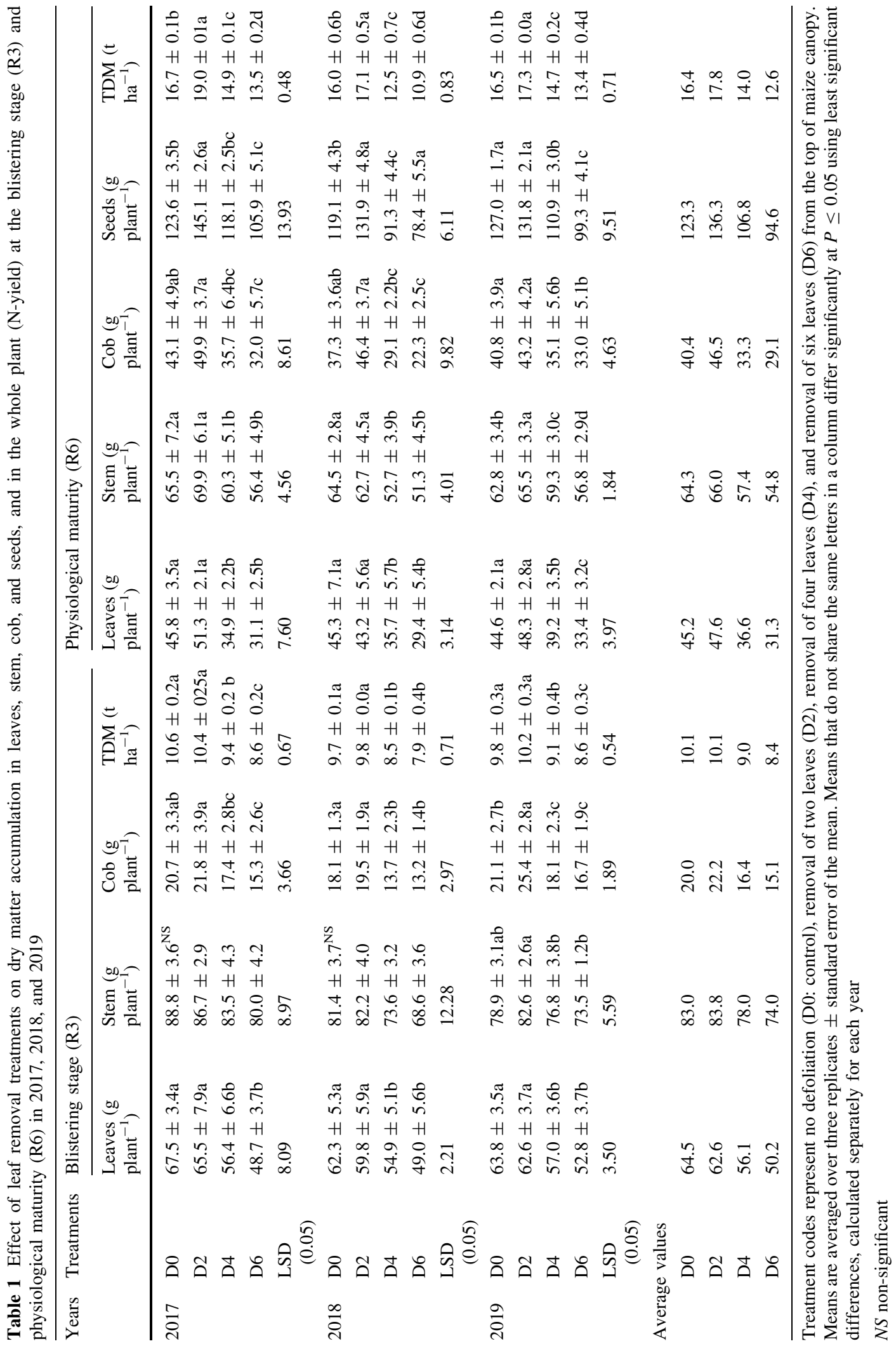




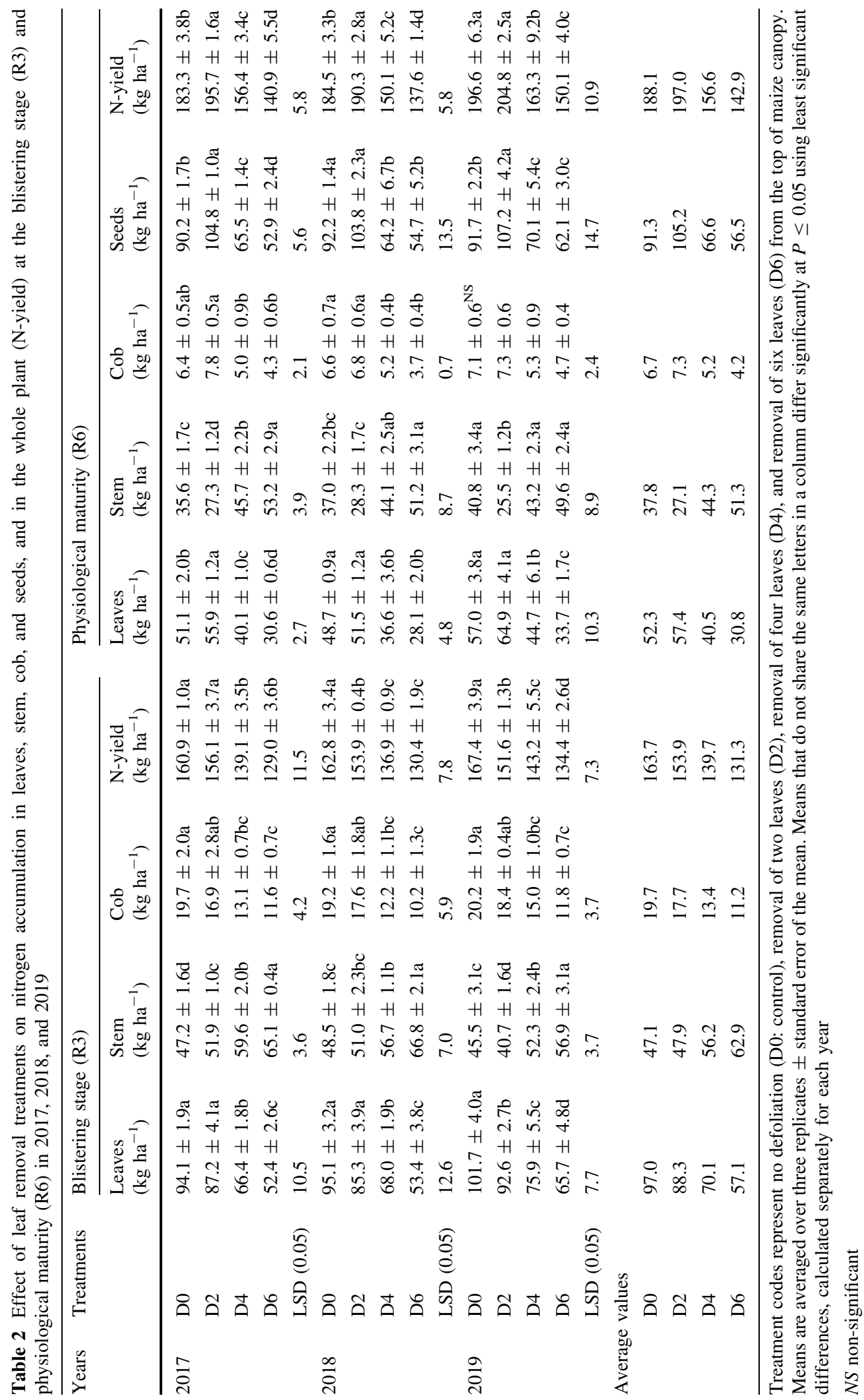


(a) Nitrogen Uptake

घD0 D2 $\square \mathrm{D} 4$ 曰D6

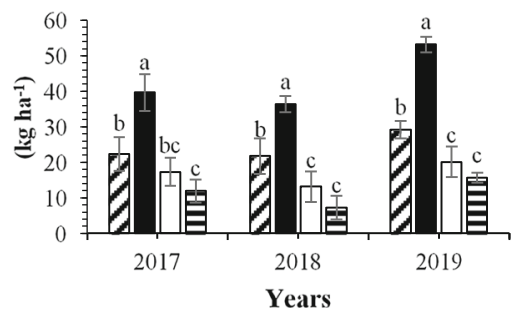

(b) Phosphorus Uptake

๑D0 -D2 $\square \mathrm{D4}$ 曰D6 (c) Potassium Uptake

ロD0 D2 $\square \mathrm{D} 4 \square \mathrm{D} 6$
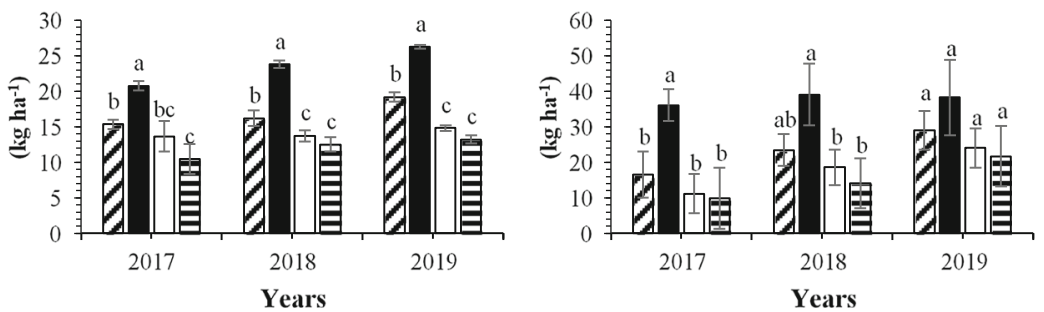

Fig. 2 Nitrogen (a), phosphorus (b), and potassium (c) uptake during the reproductive phase (from blistering stage to physiological maturity) of maize as affected by different leaf removal treatments in 2017, 2018, and 2019. Treatment codes represent no defoliation (D0: control), removal of two leaves (D2), removal of four leaves (D4), and removal of six leaves

Different leaf removal treatments had a significant impact on $\mathrm{P}$ uptake in maize. The highest P-yield was obtained in treatments D0 and D2 at R3 and R6, respectively. Averaged over the years, at R3, the P-yield of treatments D2, D4, and D6 was lower than that of treatment D0 by an average of $6 \%, 15 \%$, and $24 \%$, respectively. While at R6, the P-yield of treatment D2 was $9-11 \%$ greater than that of the control from 2017 to 2019. Leaf removal treatments affected the $\mathrm{P}$ content at the organ level in maize at both sampling stages. At R3, leaf removal treatments decreased $\mathrm{P}$ content in leaves, stem, and cob by an average of $9 \%, 4 \%$, and $6 \%$ in $\mathrm{D} 2,18 \%, 11 \%$, and $18 \%$ in D4, and $28 \%, 20 \%$, and $25 \%$ in D6, respectively in all experimental years compared with the corresponding values in D0. However, at R6, removal of two leaves (D2) increased the $\mathrm{P}$ content of remaining leaves (by 29\%), cob (by 19\%), and seeds (by 19\%), while it decreased the P content of stem (by 30\%) as compared to no leaf removal treatment (D0). Different leaf removal treatments significantly affected the total P uptake during the seed filling phase from R3 to R6 (Fig. 2b). From R3 to R6, the average highest (23.6 $\mathrm{kg} \mathrm{ha}^{-1}$ ) total $\mathrm{P}$ uptake was obtained in D2, while the average lowest $\left(12.1 \mathrm{~kg} \mathrm{ha}^{-1}\right)$ total $\mathrm{P}$ uptake was found under D6. Overall, averaged over the years, the total P uptake was enhanced by $40 \%$ in $\mathrm{D} 2$ as compared to D0, while it declined by $17 \%$ and $29 \%$ under D4 and D6, respectively.

(D6) from the top of maize canopy. Means are averaged over three replicates \pm standard error of the mean. Means that do not share the same letters in a column differ significantly at $P \leq 0.05$ using least significant differences, calculated separately for each year

Potassium uptake

Table 4 presents the K-yield under different leaf removal treatments. At R3 and R6, the average highest K-yields, $181.2 \mathrm{~kg} \mathrm{ha}^{-1}$ and $212.0 \mathrm{~kg} \mathrm{ha}^{-1}$, were measured in D0 and D2, respectively, while the average lowest $\mathrm{K}$-yields of $134.8 \mathrm{~kg} \mathrm{ha}^{-1}$ and $150.0 \mathrm{~kg} \mathrm{ha}^{-1}$ were found under treatment D6 over the 3 years of the experiment. Overall, at R6, K-yield was increased by $4 \%$ in D2 as compared to D0, while it decreased by $16 \%$ in D4 and $27 \%$ in D6. In this experiment, $\mathrm{K}$ uptake during the seed filling phase (from R3 to R6) was also affected by the leaf removal treatments (Fig. 2c). Treatment D2 enhanced the K uptake by $65 \%$ over the 3 years of this experiment compared with the corresponding values in D0. Moreover, different leaf removal treatments affected the $\mathrm{K}$ content in various organs of maize at R3 and R6. At R3, the maximum $\mathrm{K}$ content in leaves $\left(81.8 \mathrm{~kg} \mathrm{ha}^{-1}\right)$, stem $\left(82.9 \mathrm{~kg} \mathrm{ha}^{-1}\right)$, and cob $\left(16.5 \mathrm{~kg} \mathrm{ha}^{-1}\right)$ were observed in D0, while the minimum $\mathrm{K}$ content in all organs of maize was observed in D6 over the 3 years of study. However, at R6, optimum removal of leaves (D2) enhanced the K content of leaves (by 13\%), cob (by 20\%), and seeds (by 16\%), but it reduced the $\mathrm{K}$ content of stem (by $17 \%$ ) as compared to D0 over the 3 years of experiment. Overall, the $\mathrm{P}$ and $\mathrm{K}$ accumulation, uptake from R3 to R6, and distribution among various plant organs of maize in different leaf removal treatments followed the same trend in all years of experiment. 


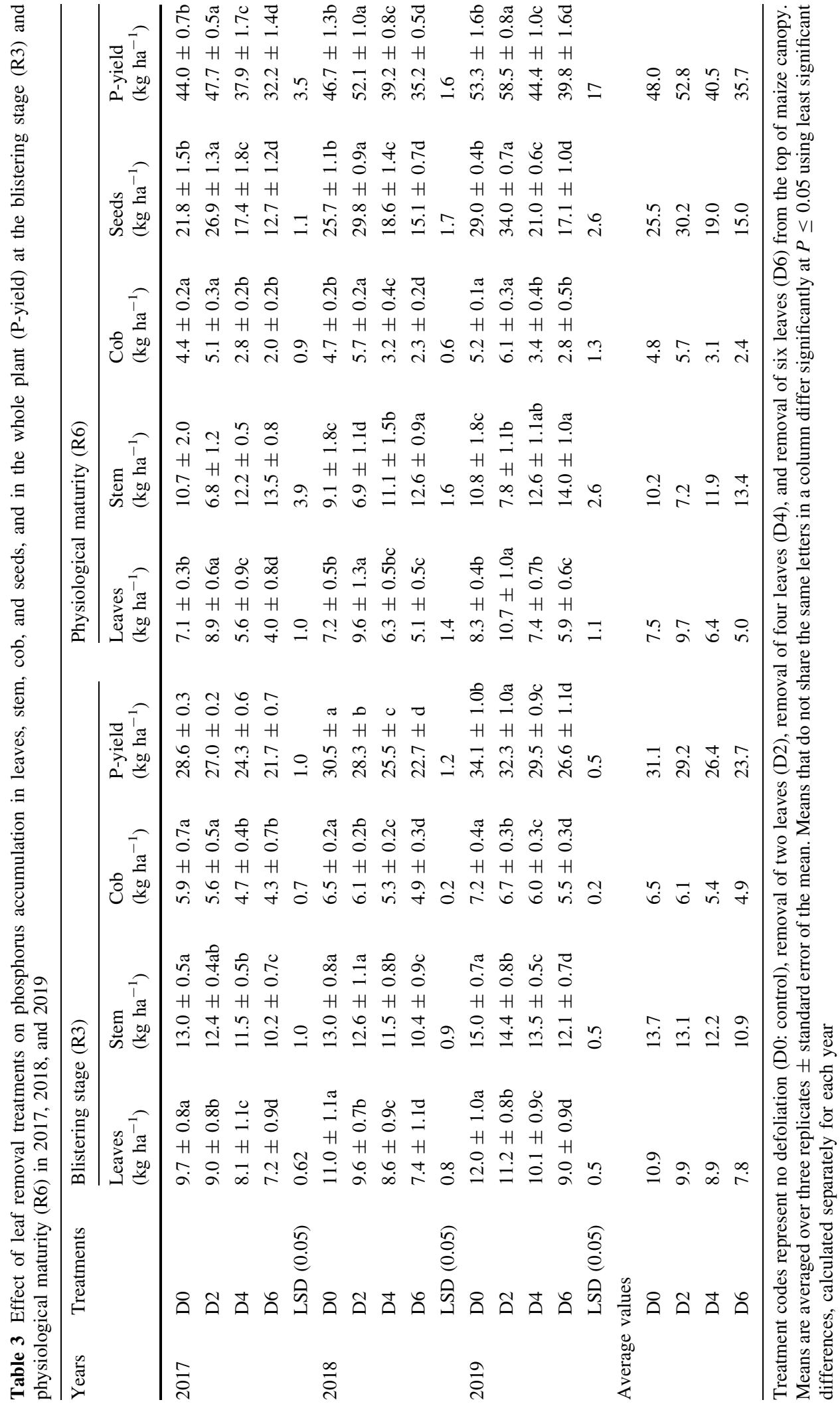




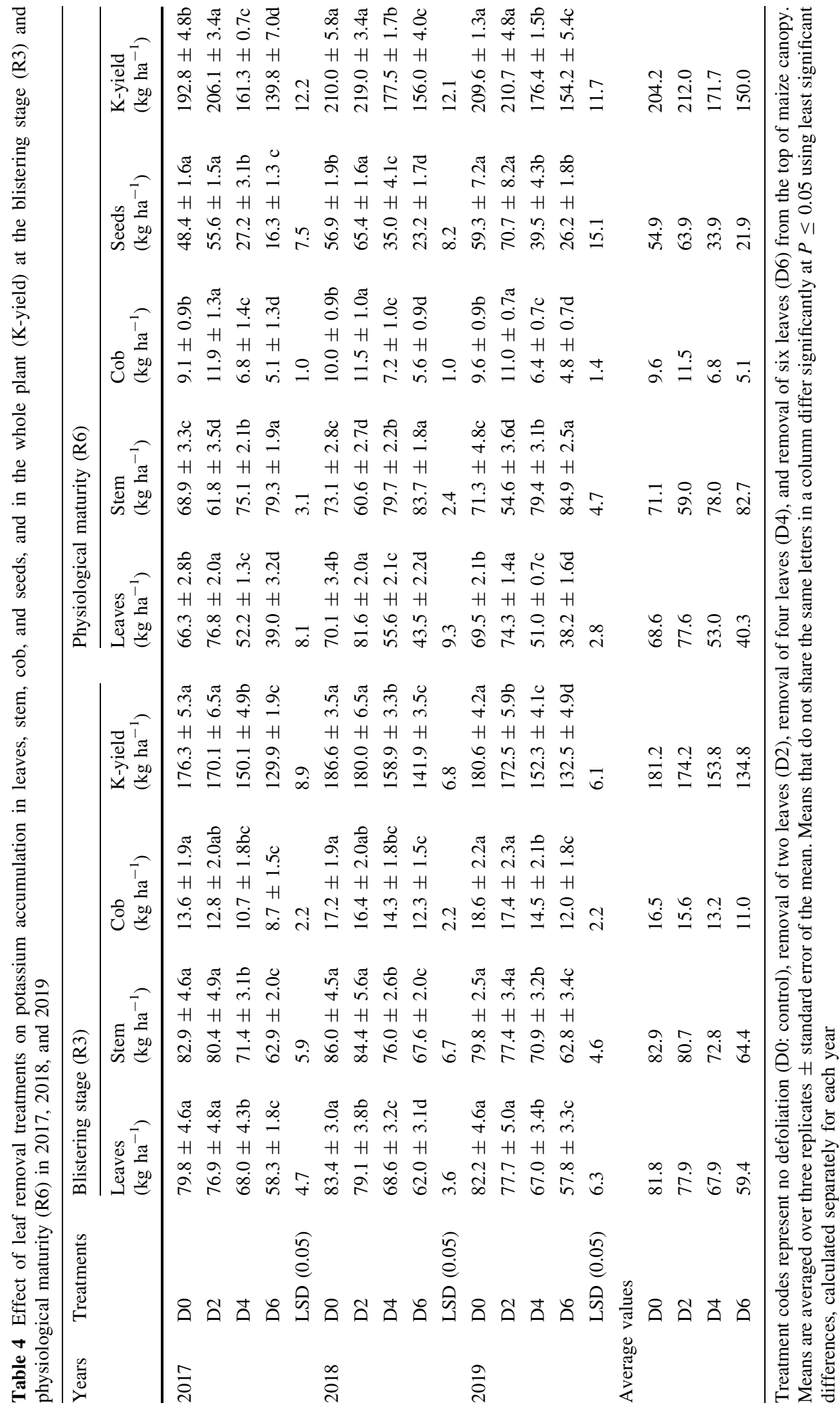



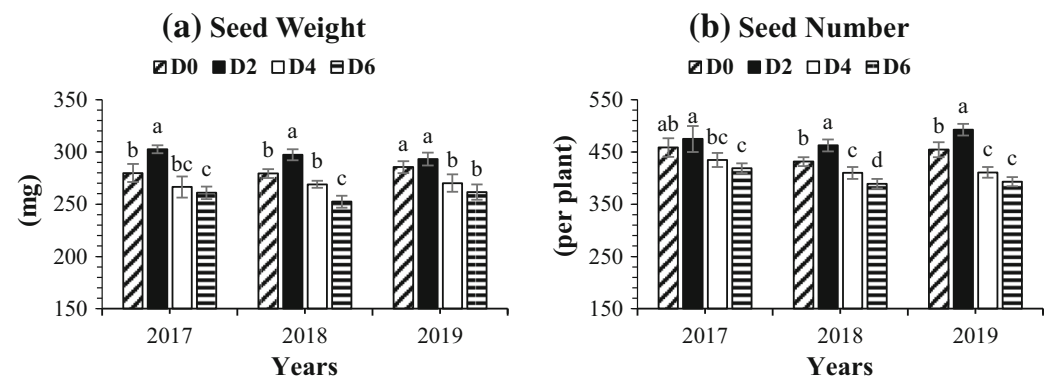

Fig. 3 Seed weight (a), seed number (b), and seed yield (c) of maize as affected by different leaf removal treatments in 2017 , 2018, and 2019. Treatment codes represent no defoliation (D0: control), removal of two leaves (D2), removal of four leaves (D4), and removal of six leaves (D6) from the top of maize

\section{Yield and yield parameters}

Figure 3 shows the yield and yield components of maize under different leaf removal treatments. The maize yield parameters, including seed weight and seed number per plant in response to different leaf removal treatments, are given in Fig. 3a, b. In all years of the experiment, leaf removal treatments exhibited a significant effect on seed weight and seed number per plant of maize plants. The average highest seed number (476.6 per plant) and seed weight (297.7 mg) were noted in D2, while the average lowest seed number (400.4 per plant) and seed weight (258.3 mg) were obtained under D6. Meanwhile, seed number per plant was significantly reduced by excessive leaf removal (D4 and D6) treatments. In contrast, the removal of two leaves (D2) significantly increased the seed number of maize plants as compared to control. For instance, averaged over the years, relative to D0, treatment D2 enhanced the seed number per plant by $6 \%$, while it reduced seed number by $7 \%$ in D4 and $11 \%$ in D6. The seed yield of maize was significantly affected by different leaf removal treatments (Fig. 3c). The highest seed yield (8.6 t ha ${ }^{-1}$ in 2017, 8.2 $\mathrm{t} \mathrm{ha}^{-1}$ in 2018 and $8.7 \mathrm{t} \mathrm{ha}^{-1}$ in 2019) was obtained in D2, and the lowest seed yield ( $6.6 \mathrm{t} \mathrm{ha}^{-1}$ in 2017, $5.9 \mathrm{t} \mathrm{ha}^{-1}$ in 2018 and $6.2 \mathrm{t} \mathrm{ha}^{-1}$ in 2019) was measured under treatment D6. Overall, averaged over the years, relative to D0, removal of two leaves (D2) enhanced the maize seed yield by $12 \%$; however, excessive leaf removal treatments D4 and D6 reduced the maize seed yield by $11 \%$ and $18 \%$, respectively. The changes in yield and yield parameters in 2019 canopy. Means are averaged over three replicates \pm standard error of the mean. Means that do not share the same letters in a column differ significantly at $P \leq 0.05$ using least significant differences, calculated separately for each year

under different leaf removal treatments were consistent with those of the previous years (2017 and 2018).

Economic analysis

Economic analysis for maize production under different leaf removal treatments is shown in Table 5. In this experiment, the highest total income from maize was obtained in treatment D2 (removal of two leaves), while the lowest total income of maize was noted under treatment D6 (removal of six leaves). Overall, averaged over the years, the total income was enhanced by $29 \%$ under treatment D2, while it was reduced by $46 \%$ under D4 and $74 \%$ under D6 compared to no leaf removal treatment D0.

\section{Discussion}

The improvement of resource use efficiency in crops requires a multi-faceted approach to enhance nutrient utilization, dry matter accumulation, and translocation to the economic parts (Raza et al. 2018a, b). This study shows that improved light transmittance during the seed filling phase (from the blistering stage to the physiological stage), influenced by the different leaf removal treatments, has significant effects on dry matter accumulation, nutrient uptake, and seed yield of maize plants. Higher light transmittance at middle strata leaves of maize in D2, as compared to D0, resulted in increased total dry matter $(+9 \%)$ and grain yield $(+12 \%)$, and it also increased the $\mathrm{N}(+5 \%), \mathrm{P}$ $(+10 \%)$, and $\mathrm{K}(+4 \%)$ uptake in maize. Overall, during the seed filling phase, the total $\mathrm{N}, \mathrm{P}$, and $\mathrm{K}$ 


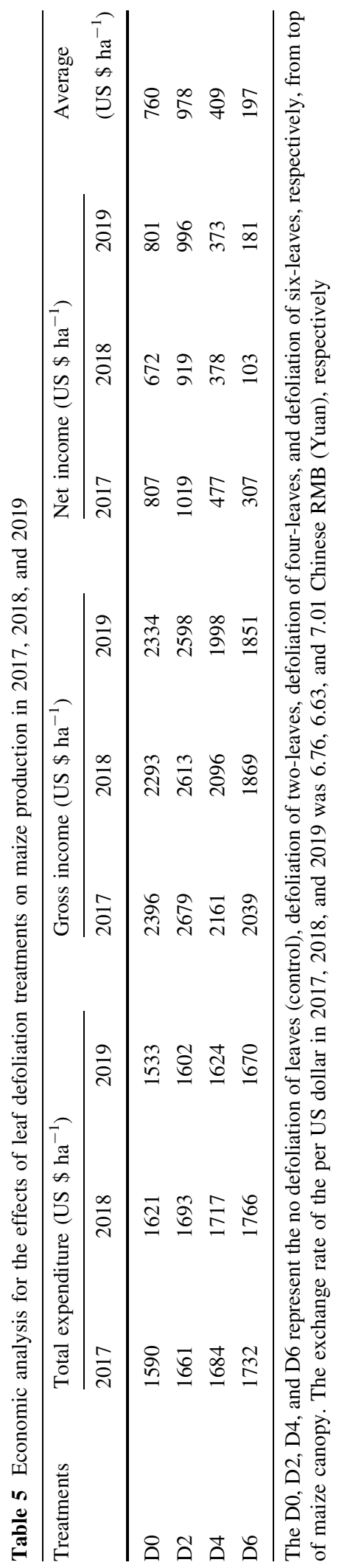

uptake under D2 were increased by $76 \%, 40 \%$, and $65 \%$, respectively, compared to D0. This experiment demonstrates that an optimum leaf removal treatment that allows better light transmittance within the maize canopy can improve dry matter and nutrient accumulation, which ultimately increases the seed yield of maize.

Dry matter accumulation with leaf removal

Dry matter accumulation and its apportioning into various plant organs were different in leaf removal and control treatments. Total dry matter accumulation (TDM) was enhanced from R3 to R6 in all treatments (D0, D2, D4, and D6), consistent with the past reported trend of TDM during the grain filling stage in other crops such as wheat, safflower, soybean, and maize (Dordas and Sioulas 2008; Papakosta and Gagianas 1991; Raza et al. 2019a, b). Previously, it was confirmed that low light transmittance at the middle strata leaves of maize plants abated the TDM (Liu et al. 2015). However, our 3 years of the experiment showed that the removal of two leaves from the maize plant enhanced the TDM and translocation to remaining leaves and seeds from R3 to R6 as compared to no leaf removal treatment. This increase might be due to the optimum light transmittance within maize (Jun et al. 2017), which enhances the current photosynthesis of remaining leaves in maize due to the increase in leaf $\mathrm{N}$ content (Li et al. 2014; Liu et al. 2017), and increases the water flow from the soil along with the uptake of major nutrients, especially during the grain filling phase (Dordas and Sioulas 2008; Elliott et al. 1997; Muchow and Davis 1988). Another possible mechanism of this improvement in TDM under D2 is directly associated with the removal of the tassel along with optimum leaf removal (D2) because the tassel reduces light transmittance within maize plants up to $19 \%$ (Karam et al. 2010). The apical dominance in maize during seed filling is expressed through the tassel, which mediates the carbohydrate partitioning in favor of vegetative parts (stem and apex) at the expense of economic parts (ears and seeds) (Damptey 1982; Medford and Klee 1989). On the other hand, excessive removal of leaves from the canopy (D4 and D6) led to huge reductions in TDM and its translocation to remaining leaves and seeds. The reduction in TDM in D4 and D6 could be due to the lower leaf area index that could partially account 
for the decreased photosynthesis of maize plants (Raza et al. 2019a), and declined translocation of dry matter to seeds suggesting that excessive leaf removal favored the retention of carbohydrates in the stem (Khanna-Chopra and Maheswari 1998), which impedes the seed filling from R3 to R6 in maize (Liu et al. 2015). Thus, it appears that during the seed filling phase (from R3 to R6), maize plants having the opportunity to increase their TDM and translocation to remaining leaves and seeds if the growing conditions become favorable such as improved light transmittance within the canopy, which can be maintained by optimum removal of leaves from maize plants, as observed in this study for 3 years.

Nutrient accumulation and partitioning with leaf removal

Environmental factors and microclimate, e.g., the light environment of crop plants, can influence the uptake of N, P, and K (Papakosta and Gagianas 1991; Raza et al. 2019c, d). We found that N, P, and K uptake and partitioning among various plant organs of maize at R3 (leaves, stem, and cob) and R6 (leaves, stem, cob, and seed) were altered significantly in all treatments, due to the high and low requirements of these nutrients in different plant organs. Previously, researchers have reported that seeds are the most vital and active sink for nutrients and photoassimilates in cereals after the vegetative phase (Kitonyo et al. 2018). Similarly, N, P, and $\mathrm{K}$ accumulation in stem and cob diminished from R3 to R6, suggesting the accumulation and remobilization of $\mathrm{N}, \mathrm{P}$, and $\mathrm{K}$ to other plant organs of maize, possibly to leaves and seeds as the $\mathrm{N}, \mathrm{P}$, and $\mathrm{K}$ accumulation in leaves and seeds were increased. Additional partitioning of nutrients to leaves is crucial to maintain the higher rate of photosynthesis, and the $\mathrm{N}, \mathrm{P}$, and $\mathrm{K}$ accumulation in maize after the vegetative stage depends on the concurrent photoassimilate production of maize, which governs the allocation pattern of nutrients in different plant organs. Increases in nutrient uptake due to optimum leaf removal (D2) have been attributed to improved light transmittance within maize, which increased the photosynthetic- and transpiration-rate of the most competent leaves of maize at middle strata (Liu et al. 2015). Another benefit of having a better light transmittance within maize is its associated higher root development and proliferation biomass because an improvement in light intensity significantly increased the root biomass of maize under closed planting systems (Raza et al. 2019c, d). This indicates the potential to increase nutrient uptake because, with greater root biomass, nutrients can be taken up from deeper depths and that the roots can explore a greater soil volume. Therefore, managing crop canopies by partly removing leaves from the top of the maize canopy can improve the light transmittance within maize, which ultimately enhanced the accumulation of nutrients (Raza et al. 2019c). Thus, tailoring of maize canopies, especially during the seed filling phase, could improve nutrient accumulation by optimizing light transmittance within maize and improving the microenvironment of the remaining leaves.

Nutrient uptake with leaf removal

In previous studies, scientists have inferred that shading environments reduced the uptake of $\mathrm{N}, \mathrm{P}$, and $\mathrm{K}$ in crops (Chen et al. 2017; Liu et al. 2017; Zhou et al. 2019). However, treatment D2 improved the light transmittance within maize, which favored the partitioning of dry matter and carbohydrates towards roots, and ultimately increased the nutrient uptake (Henry and Raper Jr 1991; Palmer et al. 1996; Raza et al. 2019c). In line with this, researchers have confirmed that adequate availability of light within maize canopy delayed the process of leaf senescence (Liu et al. 2015) and enhanced the net photosynthesis of remaining leaves, which increased $\mathrm{N}, \mathrm{P}$, and $\mathrm{K}$ uptake in maize (Raza et al. 2019d; Spiertz and Ellen 1978). In contrast, compared with D0, the absorption of $\mathrm{N}, \mathrm{P}$, and $\mathrm{K}$ were decreased in D4 and D6 treatments. Because the excessive $\mathrm{N}, \mathrm{P}$, and $\mathrm{K}$ remobilization from leaves to seeds accelerated the leaf senescence and reduced the photosynthetic activity of remaining leaves, which was not favorable for the uptake of $\mathrm{N}, \mathrm{P}$, and $\mathrm{K}$ in maize during seed filling phase. Previously, some scientists assumed that the $\mathrm{N}$ absorbed before the seed filling phase in cereal crops could account for 70-90\% of the total $\mathrm{N}$ in seeds (Cox et al. 1985; Heitholt et al. 1990), and post-vegetative $\mathrm{N}$ uptake in maize seeds was reduced by the decreased net photosynthesis from silking to physiological maturity (Liu et al. 2017), caused by the mutual shading which reduces the light transmittance within maize (Jun et al. 2017). However, our results corroborated that increasing light transmittance within maize 
could enhance the uptake of $\mathrm{N}$ during the seed filling phase, which would increase the maize seed yield, as observed in this study. In contrast to $\mathrm{N}$ uptake, the uptake of $\mathrm{P}$ takes place throughout the growth of crop plants (Batten 1992), and a significant amount of $P$ uptake was reported during the seed filling stage (Papakosta 1994), as noted in this experiment. In addition, the impact of leaf removal treatments on the uptake of $\mathrm{K}$ during the seed filling was not fully explained previously; however, in this experiment, we observed that optimum leaf removal (D2) increased the uptake of $\mathrm{K}$ as it did for $\mathrm{N}$ and $\mathrm{P}$, but excessive leaf removal treatments (D4 and D6) causes a reduction in the uptake of $\mathrm{K}$ during the seed filling phase. Taken together, the results of this study reinforce the effect of greater $\mathrm{N}, \mathrm{P}$, and $\mathrm{K}$ uptake during the seed filling phase (from R3 to R6) of maize. The higher uptake of N, P, and $\mathrm{K}$ in $\mathrm{D} 2$ increased the length of the seed filling phase by delaying leaf senescence and maintaining a high supply of photoassimilates to developing seeds in maize.

\section{Maize yield with leaf removal}

Removal of two leaves from maize plants (D2) produced the highest seed yield, with an improvement of $12 \%$ in $2017,14 \%$ in 2018 , and $11 \%$ in 2019 compared to no leaf removal treatment (D0). Further, we noted that different leaf removal treatments significantly improved seed weight $(\mathrm{mg})$ and seed number per plant, and the maximum seed weight and seed number per plant were found under D2 treatment in all 3 years of the experiment. Hence, the highest seed yield in D2 was attributed to heavier maize seeds and higher seed number per plant. Another possible reason for these results was the availability of extra carbohydrates for maize ears because the photoassimilates and nutrients required for the development of top leaves were channeled to the developing ears, the result reflected in fewer barren stalks and heavier seeds (Grogan 1956). Therefore, we conclude that the higher seed yield of maize in D2 is associated with the improved light transmittance within the canopy during the seed filling phase, leading to fewer barren ears than in D0. Additionally, the higher seed weight and seed number per plant under D2 were related to higher carbohydrate production and nutrient uptake which were the result of higher current photosynthesis of maize plants (Liu et al. 2017), leading to a greater distribution of dry matter and $\mathrm{N}, \mathrm{P}$, and $\mathrm{K}$ to developing seeds during the seed filling phase. However, excessive leaf removal treatments significantly reduced (11\% in D4 and 18\% in D6) the maize seed yield, which might be due to the lower leaf area of maize plants in D4 and D6 which reduced the final seed weight and seed number per plant, as reported in previous studies (Khanna-Chopra and Maheswari 1998; Liu et al. 2017; Tollenaar and Daynard 1978).

The economic viability of leaf removal treatments

The economic analysis of this experiment concluded that higher net income $(26 \%, 37 \%$, and $24 \%$, in 2017 , 2018, and 2019, respectively) was achieved in D2 than in other treatments. Removal of two leaves from maize plants increased the light transmittance within the canopy and dry matter accumulation, and the uptake of $\mathrm{N}, \mathrm{P}$, and $\mathrm{K}$, especially during the seed filling phase, which ultimately enhanced maize production and provided higher income for farmers in low sunlight conditions.

\section{Conclusion}

Based on our experiment, our results showed that higher nutrient uptake from the soil is possible during the seed filling phase of maize by increasing the light transmittance within the canopy, and farmers can obtain higher net income by manipulating the maize canopies, especially under low sunlight conditions. Furthermore, our results provide a new agronomic approach to farmers, especially of low light regions, such as the high mountainous areas of the world. They can adopt this new agronomic practice to increase their maize yield and income by manipulating crop canopies. However, further experiments are required to fully understand the nature of the internal signals and mechanism controlling and regulating the nutrient uptake in maize, especially during the seed filling phase.

Acknowledgements The research was supported by the National Key Research and Development Program of China (2016YFD0300209), the National Nature Science Foundation (31571615), and Program on Industrial Technology System of National Soybean (CARS-04-PS19). Authors thanks to Stewart Smock Higgins, Department of Biological Systems Engineering, Washington State University Pullman USA, for 
helping in the English editing and improvement of the article. Muhammad Ali Raza's thanks to MUHAMMAD (Salallahu Alayhi Wasalam) for enlightening his life.

\section{Compliance with ethical standards}

Conflict of interest The authors declare that they have no conflict of interest.

\section{References}

Arduini I, Masoni A, Ercoli L, Mariotti M (2006) Grain yield, and dry matter and nitrogen accumulation and remobilization in durum wheat as affected by variety and seeding rate. Eur J Agron 25:309-318

Batten GD (1992) A review of phosphorus efficiency in wheat. Plant Soil 146:163-168

Borrás L, Slafer GA, Otegui ME (2004) Seed dry weight response to source-sink manipulations in wheat, maize and soybean: a quantitative reappraisal. Field Crops Res 86:131-146

Chen P et al (2017) Effects of reduced nitrogen inputs on crop yield and nitrogen use efficiency in a long-term maizesoybean relay strip intercropping system. PLoS ONE 12:e0184503

Connor DJ, Loomis RS, Cassman KG (2011) Crop ecology: productivity and management in agricultural systems. Cambridge University Press, Cambridge

Cox MC, Qualset CO, Rains DW (1985) Genetic variation for nitrogen assimilation and translocation in wheat. I. Dry matter and nitrogen accumulation. Crop Sci 25:430-435

Damptey H (1982) The effect of water deficit, hormones and mineral nutrition on the growth of axillary inflorescence in Zea Mays L. Ghana J Sci

Dordas CA, Sioulas C (2008) Safflower yield, chlorophyll content, photosynthesis, and water use efficiency response to nitrogen fertilization under rainfed conditions. Ind Crops Prod 27:75-85

Elliott D, Reuter D, Reddy G, Abbott R (1997) Phosphorus nutrition of spring wheat (Triticum aestivum L.). 1. Effects of phosphorus supply on plant symptoms, yield, components of yield, and plant phosphorus uptake. Aust J Agric Res 48:855-868

Feng LY et al (2019) Narrow-wide row planting pattern improves the light environment and seed yields of intercrop species in relay intercropping system. PLoS ONE 14:e0212885

Grogan CO (1956) Detasseling responses in corn 1. Agronomy J 48:247-249

Guitman MR, Arnozis PA, Barneix AJ (1991) Effect of sourcesink relations and nitrogen nutrition on senescence and $\mathrm{N}$ remobilization in the flag leaf of wheat. Physiol Plant 82:278-284

Heitholt JJ, Croy L, Maness N, Nguyen H (1990) Nitrogen partitioning in genotypes of winter wheat differing in grain N concentration. Field crops Res 23:133-144
Henry LT, Raper CD Jr (1991) Soluble carbohydrate allocation to roots, photosynthetic rate of leaves, and nitrate assimilation as affected by nitrogen stress and irradiance. Bot Gaz 152:23-33

Iqbal A, Hidayat Z (2016) Potassium management for improving growth and grain yield of maize (Zea mays L.) under moisture stress condition. Sci Rep 6:34627

Jun X, Ling G, Shi Z-G, Zhao Y-S, Zhang W-F (2017) Effect of leaf removal on photosynthetically active radiation distribution in maize canopy and stalk strength. J Integr Agric 16:85-96

Karam D, PereiraFilho IA, Magalhães PC, Paes MCD, Silva JAA, Gama JDCM (2010) Resposta de plantas de milho à simulação de danos mecânicos. Revista Brasileira de Milho e Sorgo 9:201-211

Kefu Z (1981) Effect of the leaves of different positions in maize on the corn yield and the photosynthetic properties of those leaves after the growing out of the female flowers. Acta Agrono Sin 4:005

Khanna-Chopra R, Maheswari M (1998) Effect of altering source availability on expression of sink capacity in a maize hybrid and its parents. Eur J Agron 9:101-107

Kitonyo OM, Sadras VO, Zhou Y, Denton MD (2018) Nitrogen supply and sink demand modulate the patterns of leaf senescence in maize. Field crops Res 225:92-103

Li T, Liu L-N, Jiang C-D, Liu Y-J, Shi L (2014) Effects of mutual shading on the regulation of photosynthesis in fieldgrown sorghum. J Photochem Photobiol B 137:31-38

Liu T, Gu L, Dong S, Zhang J, Liu P, Zhao B (2015) Optimum leaf removal increases canopy apparent photosynthesis, 13 C-photosynthate distribution and grain yield of maize crops grown at high density. Field Crops Res 170:32-39

Liu T, Huang R, Cai T, Han Q, Dong S (2017) Optimum leaf removal increases nitrogen accumulation in kernels of maize grown at high density. Sci Rep 7:39601

Medford J, Klee H (1989) Manipulation of endogenous auxin and cytokinin levels in transgenic plants. In: UCLA symposia on molecular and cellular biology (USA)

Miralles DJ, Slafer GA (2007) Sink limitations to yield in wheat: How could it be reduced? J Agric Sci 145(2):139-149

Muchow R, Davis R (1988) Effect of nitrogen supply on the comparative productivity of maize and sorghum in a semiarid tropical environment II. Radiation interception and biomass accumulation. Field Crops Res 18:17-30

Palmer S, Berridge DM, McDonald A, Davies W (1996) Control of leaf expansion in sunflower (Helianthus annuus L.) by nitrogen nutrition. J Exp Bot 47:359-368

Papakosta DK (1994) Phosphorus accumulation and translocation in wheat as affected by cultivar and nitrogen fertilization. J Agron Crop Sci 173:260-270

Papakosta DK, Gagianas A (1991) Nitrogen and dry matter accumulation, remobilization, and losses for Mediterranean wheat during grain filling. Agron J 83:864-870

Peel MC, Finlayson BL, McMahon TA (2007) Updated world map of the Köppen-Geiger climate classification. Hydrol Earth Syst Sci 11:1633-1644

Prystupa P, Savin R, Slafer GA (2004) Grain number and its relationship with dry matter, $\mathrm{N}$ and $\mathrm{P}$ in the spikes at heading in response to $\mathrm{N} \times \mathrm{P}$ fertilization in barley. Field Crops Res 90:245-254 
Raza M et al (2018a) Effect of sulphur application on photosynthesis and biomass accumulation of sesame varieties under rainfed conditions. Agronomy 8:149

Raza MA et al (2018b) Sulphur application increases seed yield and oil content in sesame seeds under rainfed conditions. Field Crops Res 218:51-58. https://doi.org/10.1016/j.fcr. 2017.12.024

Raza MA et al (2019a) Optimum leaf excision increases the biomass accumulation and seed yield of maize plants under different planting patterns. Ann Appl Biol 175:1-15. https://doi.org/10.1111/aab.12514

Raza MA et al (2019b) Maize leaf-removal: a new agronomic approach to increase dry matter, flower number and seedyield of soybean in maize soybean relay intercropping system. Sci Rep 9:1-13

Raza MA et al (2019c) Optimum leaf defoliation: a new agronomic approach for increasing nutrient uptake and land equivalent ratio of maize soybean relay intercropping system. Field Crops Res 244:107647

Raza MA et al (2019d) Effect of planting patterns on yield, nutrient accumulation and distribution in maize and soybean under relay intercropping systems. Sci Rep 9:4947

Sinclair TR, Rufty TW, Lewis RS (2019) Increasing photosynthesis: unlikely solution for world food problem. Trends Plant Sci 24:1032-1039

Spiertz J, Ellen J (1978) Effects of nitrogen on crop development and grain growth of winter wheat in relation to assimilation and utilization of assimilates and nutrients. Neth J Agric Sci 26:210-231

Tollenaar M, Daynard T (1978) Effect of defoliation on kernel development in maize. Can J Plant Sci 58:207-212

Valladares F, Niinemets Ü (2008) Shade tolerance, a key plant feature of complex nature and consequences. Annu Rev Ecol Evol Syst 39:237-257

Vouillot M, Devienne-Barret F (1999) Accumulation and remobilization of nitrogen in a vegetative winter wheat crop during or following nitrogen deficiency. Ann Bot 83:569-575

Wu Y, Gong W, Yang W (2017) Shade inhibits leaf size by controlling cell proliferation and enlargement in soybean. Sci Rep 7:9259. https://doi.org/10.1038/s41598-01710026-5

Yang F et al (2017) Effect of aboveground and belowground interactions on the intercrop yields in maize-soybean relay intercropping systems. Field Crops Res 203:16-23. https:// doi.org/10.1016/j.fcr.2016.12.007

Zhou T, Wang L, Gao Y, Du YL, Zhao L, Guo LW (2019) Interactions between light intensity and phosphorus nutrition affect the $\mathrm{P}$ uptake capacity of maize and soybean seedling in a low light intensity area. Front Plant Sci 10:183

Publisher's Note Springer Nature remains neutral with regard to jurisdictional claims in published maps and institutional affiliations. 